\author{
Research Article \\ (c) 2021 Reema Mahmoud Abod AlOqlah. \\ This is an open access article licensed under the Creative Commons \\ Attribution-NonCommercial 4.o International License \\ (https://creativecommons.org/licenses/by-nc/4.o/)
}

\title{
Obstacles of TQM Implementation in Saudi Universities: An Empirical Study
}

\author{
Reema Mahmoud Abod AlOqlah \\ Assistant Professor, Self- Department, \\ Deanship of the Preparatory Year and Supporting Studies, \\ Imam Abdurrahman AlFaisal University, \\ P.O. Box: 1982, Dammam 34212, Saudi Arabia
}

DOI: https://doi.org/10.36941/ajis-2021-0109

\section{Abstract}

This study aims to identify the obstacles to the application of total quality management at the Saudi University from the faculty members' point of view and to identify the significance of statistical differences in the obstacles to the application of total quality management in Saudi universities from the viewpoint of faculty members according to the variables of gender, academic rank, and college. To achieve the study objectives, the researcher used the descriptive design and quantitative approach, depending on the questionnaire as the main instrument for collecting study data. The study was applied to a sample consisting of (350) faculty members at Imam Abdulrahman bin Faisal University, who were selected randomly, the number of questionnaires valid for analysis (277) questionnaires. Among the most prominent results of this study showed that top management obstacles, human resources obstacles, student's obstacles, financial resources, educational technology obstacles, community service obstacles, obstacles to scientific research, organizational culture obstacles, and educational curriculum obstacles are affecting on implementation of TQM at Imam Abdulrahman bin Faisal University from point of view faculty members. The results showed the top management obstacles came in the first rank among the obstacles that affect TQM implementation, followed by student's obstacles, while financial resources obstacles and human resources obstacles come in the last obstacles affect TQM implementation at Imam Abdulrahman bin Faisal University from point of view faculty members. Also, the results showed there are no significant statistical differences in the obstacles to the application of total quality management according to the variables of gender, academic rank, and college.

Keywords: Total Quality Management, Obstacles, Quality, Universities, Saudi

\section{Introduction}

The growth of a more competitive community needs all to compete in a healthy way. Likewise, with an educational institution. The growth of higher education institutions is interconnected and involves a systematic quality management framework as a tool and style of work to handle different aspects of educational administration (Almurshidee, 2017). The quality of higher education means the ability of all the characteristics and features of the educational product to meet the requirements of the student, market, society, and all internal and external beneficiaries (Zanqar, Khatibi, Azam \& Tham, 2019). Achieving the quality of education requires directing all human resources, policies, 
systems, curricula, processes, and infrastructure in order to create favorable conditions for innovation and creativity to ensure that the product is met the educational requirements that prepare the student to reach the level that we all strive to achieve (Zanqar et al., 2019).

Universities at the present time are an icon of the rise of peoples and nations, the title of their greatness, civilization, advancement, and an essential axis around which cultural life revolves in its comprehensive sense, and with its intellectual, literary, scientific, and technological dimensions (Setiawan, 2019). Quality in universities depends on an integrated system of educational information, with attention to conducting many studies to identify the best methods for applying the principles of total quality after diagnosing the existing situation, knowing the deficiencies, and working to remedy them to reach a better (Bruçaj, 2018). One of the most important entrances to evaluating university performance is the approach to Total Quality Management (TQM) (Kigozi \& On, 2019).

TQM is a modern management philosophy that contains a number of directed modern concepts that are based on a combination of administrative means, innovative efforts, and specialized technical skills in order to raise the level of performance and continuous improvement and development (Sajjad \& Syed, 2017). The concern of TQM in educational institutions, especially universities, does not mean making them commercial institutions that seek to double their profits (Sabra, Abd Elzaher \& Mahmoud, 2020). This approach should be used to develop educational administrative methods in order to achieve the quality of education and in order to double benefit for all beneficiaries of educational efforts such as community with all institutions and members in the field of education (Kistiani \& Permana, 2020).

In the Kingdom of Saudi Arabia, there are many phenomena of deficiency in the quality of education, whereby the education system fails to meet the requirements of development in the Saudi society such as deficiencies of multiple professional competencies, and the graduates 'poor performance in the labor market that related to fundamentals, skills, language, and behaviors (Almurshidee, 2017; Armor, Jnidi \& Alaqramaiti, 2019). The Kingdom of Saudi Arabia has established the National Commission for Academic Accreditation and Assessment in order to supervise universities to assist and even force them to apply the concepts of TQM (Armor et al., 2019).

In order to implement TQM in the Universities, the obstacles facing its application must be known (Sabra et al., 2020). Therefore, this study focused on the obstacles facing Saudi Universities in the application of TQM by achieving the following objectives:

1. To identify the obstacles to the application of total quality management at the Saudi University from the faculty members' point of view.

2. To identify the significance of statistical differences in the obstacles to the application of total quality management in Saudi universities from the viewpoint of faculty members according to the variables of gender, academic rank, and college.

\section{Literature Review}

The concept and obstacles to the effective applying of TQM are presented in this section.

\subsection{Quality concept}

Various well-known concepts of quality exist. Hossin, Islam, and Uddin (2018) defined quality as a set of principles and technical means that lead to the continuous improvement of performance at all levels of operations, functions, and outputs by using the available human and material resources to meet the needs of the beneficiaries and work to achieve satisfaction. Also, it is defined as the degree to which the apparent and implicit needs and expectations are satisfied through a set of pre-defined main characteristics of the beneficiaries (Surendran, 2018).

Quality in education systems is based on the principle of quality which defined by Deming's, Juran's, and Ishikawa who defined it as standards that aimed to create meaning to lives and to build a better world through provide students with the necessary skills and learning circumstances they need 
(Hasan, Islam, Shams \& Gupta, 2018). According to Kigozi (2019), the quality of education is an administrative philosophy of university leadership that focuses on satisfying the needs of students and beneficiaries in order to achieve the growth of the university and reach its goals, and it guarantees great effectiveness and high competence in the scientific and research field that ultimately lead to excellence and distinction. While Bruçaj (2018) defined it as global standards for measurement and recognition, moving from a culture of minimalism to a culture of perfection and discrimination, and considering the future as a goal we seek.

Quality includes efficiency and effectiveness both, where efficiency means: the optimal use of available resources in order to obtain good results, and effectiveness, in its simplest sense, means reaching goals (Abd-Elwahed \& El-Baz, 2018). The justification behind concern for the education quality is that the product of educational institutions is considered the most valuable product in all societies (Ezeani \& Ibijola, 2017). The success of non-educational organizations depends mainly on the success of educational systems to prepare and qualifying community members (Zanqar et al., 2019).

According to Hossin et al. (2018) and Hasan et al. (2018), the reasons for the interest in quality in the field of education are as follows:

1. Interaction with world cultures and openness to human experiences.

2. Preparing youth to face the challenges of globalization according to an integrated moral system.

3. Bringing about change in education according to an integrated institutional strategy aimed at continuous development.

These reasons prompted many countries and institutions to adopt new philosophies for the development of education systems, such as the philosophy of TQM.

\subsection{TQM: Concept, History, Principles, and Benefits}

TQM includes several concepts; 'Total' is the first concept that means integral or involvement of all persons who share in the production services or processes and confirming continuous improvement of everything and everybody in an institution (Hasan et al., 2018). The second concept is 'Quality' that defined in the context of TQM as a dynamic state that meets or exceeds beneficiaries' desires, preferences, needs, and requirements (Bruçaj, 2018). The last concept is 'Management', which comprises all people in an institution who manages processes according to their positions and roles, where cannot reach a good quality without good leadership and management (Kigozi \& On, 2019).

The concept of TQM is based on many ideas, principles, and laws that any organization can adopt in order to reach excellence (Surendran, 2018), which leads us to many definitions of the concept of TQM. Pushpa (2016) pointed out that TQM is a modern management philosophy that takes a comprehensive management approach or system based on bringing about positive radical changes to everything within the organization so that those changes include thought, behavior, values, organizational beliefs, management concepts, and the style of managerial leadership; to reach the highest quality output. According to Ravindran and Kamaravel (2016), TQM is an approach and a set of guiding principles that represent the cornerstone of the organization's quality improvement.

In the education context, TQM refers to the total efforts made by workers in the educational field to raise the level of the graduate in line with the requirements of society and with what these efforts require of implementing a set of educational standards and specifications necessary to raise the level of the student through the concerted efforts of all workers in the field of education (AlDaibat \& Al-Daibat, 2016). Sajjad and Syed (2017) defined TQM as the university's ability to provide service to the community at a high level of outstanding quality, through which it can meet the needs and desires of students and parents. Kigozi and On (2019) defined TQM as a comprehensive philosophy of life and work in educational institutions that determines a method of administrative practice based on a set of principles that aim to provide excellent educational services to internal and external beneficiaries by creating an organizational culture environment in the university that works 
to determine the university's goals and mission.

Based on the previous definitions of TQM, it appears that it has multiple components the most important of them are four components to be taken into consideration which are as follows:

1. Constant pursuit of student satisfaction.

2. Continuous and diligent work to improve and develop quality.

3. The use of work teams, and the involvement of all workers in the institution.

4. Interest in information and developing its systems.

TQM is a management method that emerged in the 1950 and has become more diffusion since the early 1980s when researchers started looked for factors and aspects of improving quality and operational performance due to increasing global markets and competition (Hossin et al., 2018).

\subsubsection{Brief history of TQM}

TQM is a method of administration that appeared in the 1950 s and became more widespread since the1970s when investigators began to look for aspects and variables of enhancing quality because of increased competition in global markets (Hossin et al., 2018). TQM launched as a simple seeking through customers to determine the quality of products (Sajjad \& Syed, 2017). Customers can examine products to determine if these products fill their needs before buying them (Bruçaj, 2018). Those basic reactive procedures carried out by customers led to internalization in the service and manufacturing industries of constructive quality improvement initiatives (Kigozi \& On, 2019). Therefore, measures of quality had developed to a prospective look through a quality defined by the industry after it was a customer-defined interactive case to ensuring the quality of services and products (Hasan et al., 2018). To make this progression a step further, there is a development of another approach to quality assurance - interactive management or TQM. Another approach to quality assurance has been developed - reactive administration or total quality management. Thus, a new culture and a new system must be created to replace the old system, and the new system must focus on a philosophy of continuous improvement; it should begin with a formal definition by the leaders of the organization of the nature of the tasks assigned to them (Hossin et al., 2018).

\subsubsection{Principles of TQM}

Despite the several definitions of the TQM concept, there is general agreement about the most important principles that must be adopted and taken into account when trying to apply TQM successfully in general and in education in particular, these principles are (Pushpa, 2016; Almurshidee, 2017):

1. Focusing on the needs and expectations of student beneficiaries and striving to achieve them through the preparation of a strategy quality improvement.

2. Emphasizing that improvement and development is a continuing process and determination of quality levels standards.

3. Focusing on prevention rather than inspection.

4. Make decisions objectively based on facts.

5. Empowering workers and motivating them to take responsibility, give them confidence, and give them full authority to perform the work.

6. Reducing bureaucracy and multiple levels of the organizational structure.

\subsubsection{Benefits of implementation TQM in universities}

Charles, Okechukwu, and Patrick (2019) indicate that there are many benefits that the university can get through the application of TQM, namely:

1. Enhancing the level scientific of students.

2. Control and development of administrative work in the university. 
3. Improving the performance of faculty members.

4. Increasing the level of trust and cooperation among university employees.

5. Enhancing love and affection among university employees.

6. Increase loyalty of the university.

TQM interventions help with pre-empting and predicting such errors and fruitless operations, as enhancing procedures capacity gets several benefits for institutions regarding time and costs (Charles et al., 2019).

\subsection{Obstacles of TQM implementation in universities}

The implementation of TQM in organizations is not without challenges. Despite the fact that there is a lot of evidence that supports TQM's success, but the credibility of TQM has been questioned as a result of failures in a variety of organizations in various industries (Talapatra \& Uddin, 2018). This implies that there are a lot of obstacles to TQM implementation (Al-Kayed \& Al-Tahrawi, 2020). According to Charles et al. (2019), understanding the obstacles that are possible to hinder TQM implementation encourages decision-makers to devise effective methods for increasing the opportunities for successful TQM implementation.

According to the literature that several organizations in both developed and developing nations have faced various obstacles in implementing TQM. As a result, a number of studies have looked at various methods for identifying the variables that obstruct the successful adoption of TQM in these nations. Alkhatib and Alkhatib (2016) mentioned that shortage in resources of financial, shortage in a fit coordinate of output education, absence of skilled manpower required for application, lack of professional manpower necessary to the application, the resistance of change, misinterpretation of the needs of beneficiaries, lack of commitment leadership to implementation, shortage in evident cultural values are the main obstacles that facing TQM implementation in higher education included universities. In addition, a study conducted by Al-Daibat and Al-Daibat (2016) that obstacles of TQM in education includes six dimensions that are financial resources, relation with society, organizational culture, top management, educational technology, and human resources.

Sabra et al. (2020) that focuses on academic staff's perspectives has determined nine main obstacles that facing to implementation of TQM, which include:

- Educational curriculum: in terms of depth, comprehensiveness 9 complementarity, and the lack of duplication and repetition, this leads to an enrichment of information and makes those interested in it aware of everything new in the field of specialization.

- Organizational culture: The main concepts, beliefs, morals, and common norms that form the framework for an individual's activities and behaviors in the organization are referred to as organizational culture. The transfer of information between people and teams in the organization is slowed to a minimum by a lack of collaboration. In general, it is critical for managers to instill confidence and trust in their workforce by allowing employees to contribute to the development of an appropriate and respectable organizational culture, and by creating an environment conducive to the successful application of TQM.

- Obstacles to scientific research: the application of total quality management to achieve the desired goal requires continuous identification of the needs and desires of the elements of the renewed educational process, and this is achieved through scientific research processes that are actually looking for new things to move away from stagnation and stagnation and keep pace with every progress in all fields.

- community service: the community surrounding the colleges is one of the most important factors affecting the strategic planning and decision-making processes, as the community is the beneficiary of the services provided by the colleges, therefore these services must be adapted to the continuous change in the desires, needs of the community, and it is also necessary to take advantage of the experiences that distinguish the community. And the 
skills of the owners of private and public institutions that can provide a benefit to the colleges, whether material, moral, legal, advisory or others.

- Educational technology: the organization's entire employee benefits from cross-training thanks to technology. It also involves infrastructure management, which eliminates paperbased activities while also giving staff a break from mundane activities. Employees that are highly skilled and have a thorough understanding of their jobs report higher job satisfaction. As a result, technology improves the quality of employment TQM is also implemented.

- Financial resources: Any plan that cannot be implemented without funding is necessary to complete its stages well to achieve the desired goals, and its implementation requires adequate funding and its suitability for those stages. Any deficiency in one of the stages of implementing the strategic plan will negatively affect the rest of the stages so that the general goals cannot be achieved without achieving the sub-goals for each stage.

- Human resources: The effectiveness and importance of the field of developing the human cadre come at an advanced level among the priorities for the success of work in the colleges and the application of Total Quality Management in a fast and equal manner, as the efficiency and experience of the cadres in all jobs and activities positively reflect on the quality of the work performed and the decisions are taken. Therefore, decisions must be made to select, appoint, develop, train, and improve employees. With great care and consideration of these decisions as important and strategic decisions, and accordingly, there must be a strategy for the human cadre concerned with achieving all the conditions, characteristics, and policies of developing it and qualifying it for the better continuously.

- Students: As the student requires peculiarities that he derives from his research and scientific capabilities, he is the main focus in achieving the university's goals. Therefore, students are required to have some competencies and skills, including learning competencies, the adequacy of carrying out scientific research, the adequacy of using modern technology in education, and the ability to interact with local community institutions and make administrative decisions and organizational.

- Top management: It refers to the administrative process practiced by the university president, his assistants, faculty deans, department directors, and department heads, and this process consists of major elements: planning, organizing, leadership, control, and performance evaluation, and the higher the quality of the administrative process, the better the use of available financial and human resources such as buildings, libraries, laboratories, and other equipment.

\subsection{Previous studies}

In light of the researcher's review of previous studies in this field, many studies have been found that dealt issue of obstacles to the implementation of TQM in universities.

Al-Daibat and Al-Daibat (2016) identified the impact of TQM implementation obstacles on TQM level implementation at Jordanian private universities. The results showed that financial resources obstacles were ranked first in the impact on the level of TQM application, followed by relation with society obstacles, then organizational culture obstacles, top management obstacles, educational technology obstacles, and human resources obstacles respectively. In addition, there is no statistically significant effect of demographic factors (gender, age, experience, job title) on Impediments of TQM.

Hassan's (2016) study was conducted at the Faculty of Social Sciences at Imam Muhammad bin Saud Islamic University in Riyadh to explore TQM application barriers. The results showed that there are many barriers to the implementation of TQM such as the absence of unique quality requirements for academic programs, an unjustified constant change for leaders of universities, university leadership's insufficient dedication to removing barriers to the implementation of TQM, an 
expectation of fast outcomes for TQM benefits and the lack of financial motivation.

Armor et al. (2019) identified the obstacles to the application of TQM at Prince Sattam bin Abdul Aziz University, and to know the effect of gender variables, specialization, scientific qualification, and years of experience in the estimates of faculty members of obstacles. The weakness of moral incentives especially for those who excel in the application of total quality, and the least obstacles were the lack of participation of faculty members in administrative aspects. The results of the study did not show significant differences at the level of significance in the constraints of the application of TQM according to the variables of study (gender and scientific qualification) in all axes, and the variable years of experience in all axes except the educational leadership axis). The study revealed that there are statistically significant differences at the level of significance in the constraints of the application of TQM according to the variable of specialization in all the questionnaires in favor of specialization theoretical colleges, and the variable years of experience in the educational leadership axis only 5 years.

Abu Saa, Wahbi and Kloob (2019) investigated the obstacles of applying TQM to Palestine Technical University-Khadoorie from the point of view of faculty members, depending on different variables (gender variable, academic rank, and faculty) on the opinions of faculty members on the obstacles to the application of TQM. The study found the following results; the level of obstacles to the application of TQM in Palestine Technical University-Khadoorieis generally high. One of the most important obstacles is the large bureaucracy in administrative work, in addition to the weakness of human relations within the campus of the university, and the lack of awareness among faculty members on the culture of quality and its importance. The study also showed that there were no statistically significant differences in the level of obstacles to the application of TQM in Palestine Technical University-Khadoorie attributed to (gender variable, academic rank, and faculty).

The study of Alnajjar and Jawad (2019) investigated TQM implementation barriers in the Iraqi private colleges from the perspective of Faculty members. The results showed that there is a statistically significant relation between TQM implementation and teaching obstacles, scientific research constraints, and senior management constraints. Also, the faculty members agreed on the lack of requirements of TQM implementation

Kigozi (2019) investigated the challenges to the successful implementation of TQM in selected public and private primary teacher training colleges in Uganda. The results show that challenges faced the implementation of TQM are: lack of leadership commitment, poor and ineffective leadership, lack of funding and resources, lack of an integrated model of TQM, poor teacher status and morale, lack of cooperation among the staff, resistance against change by the staff, lack of proper training of staff on TQM, the ambiguity of TQM implementation, misconception among PTTC staff about TQM implementation. The study also found out that there was no statistically significant difference in the level of challenges to TQM implementation among the private and public PTTCs.

Al-Kayed and Al-Tahrawi (2020) identified principles of total quality management implementation barriers in (organizational, leadership, university administration, educational process, scientific research, and local community) dimensions in Princess Alia University College from the college's teaching staff perspective. It also aimed to find out if there are statistically significant differences between study sample estimates means for most important barriers that face total quality management principles in ( the organizational, leadership, university administration, educational process, scientific research, and local community) in Princess Alia University College due to gender or academic rank variables. The study showed several results, the most important of which is there are barriers related to total quality management implementation in the college in question. The barriers ranked as follows: barriers in the educational process dimension, barriers in the leadership dimension, barriers in the scientific research dimension, barriers in the university administration dimension, barriers in the local community dimension, and organizational barriers. The study also showed that there are no statistically significant differences in identifying barriers in TQM in Princess Alia University College due to gender, while the study showed that there are statistically significant differences in recognizing barriers of TQM due to academic rank variable. 
Sabra et al. (2020) conducted a study to identify obstacles to implementing TQM in higher education institutions from an academic staff perspective. The results showed that the high mean score of TQM application obstacles was related to financial resources, while the low mean score was related to top management. In addition, there were statistically significant differences between TQM application obstacles and personal characteristics of participants and between obstacles and application of TQM.

\section{Methodology}

In this study, a descriptive design and quantitative approach have been used to create a careful, factual, and systematic summary of the characteristics and facts of a population. Descriptive quantitative research seeks to describe or define the characteristics of the object or state of research, then presented the findings in the form of analysis (Saunders, Lewis \& Thornhill, 2016).

\subsection{Population and Sample}

The study population consisted of all faculty members in Imam Abdulrahman bin Faisal University that number (3248) members according to the annual statistical report of the Saudi Ministry of Education (2017/2018). The researcher sampled (350) faculty members based on the suggestion of Morgan's table for determining sample size. To the selection of faculty members at Imam Abdulrahman bin Faisal University, the simple random sampling technique was used. (298) questionnaires out of (350) were returned, (21) questionnaires were excluded due to the noncompletion of the answers by the respondents, thus making the number of questionnaires valid for analysis (277) questionnaires.

\subsection{Instrument of study}

In the current study, questionnaires were adopted to measure their perspectives on each item in the questionnaire by Likert scale includes five-scale from "1" (very low) to " 5 " (very high). The questionnaire was broken down into two parts. Part (1) collects background information of the respondents, such as 'Gender, academic rank, and college'. Part (2) consisted of 45 items to measures nine dimensions of obstacles of TQM Implementation are: top management obstacles include items (1-5); students obstacles include items (6-10); human resources obstacles include items (11-15); financial resources obstacles include items (16-20); educational technology obstacles include items (21-25); community service obstacles include items (26-30); obstacles to scientific research include items (31-35); organizational culture obstacles include items (35-40) and educational curriculum obstacles include items (41-45). The items in this part have been adopted based on studies by AlDaibat and Al-Daibat (2016) and Sabra et al. (2020).

\subsection{Validity of Instrument}

To ensure the validity study instrument, the instrument has been presented to (6) experts from the faculty members of Saudi universities who specialists in administrative sciences and education to verify clarity, scientific accuracy, and linguistic formulation. According to experts' comments, all items have been accepted with some minor amendments have been made to their wording.

\subsection{Reliability of Instrument}

Instrument reliability means that applying the same instrument under the same situations to the same population leads to the same findings. To verify the internal accuracy of respondents' responses Cronbach alpha test has been used. Bryman and Bell (2011) and Saunders et al. (2016) mentioned that 
the value that have (6o\%) or more expresses an acceptable value for the reliability of the responses, as shown in Table 1.

Table 1. Cronbach Alpha Test

\begin{tabular}{lc}
\hline Dimensions of obstacles of TQM implementation & Cronbach Alpha Value \\
\hline Top management obstacles & 0.716 \\
\hline Students obstacles & 0.860 \\
\hline Human resources obstacles & 0.703 \\
\hline Financial resources & 0.744 \\
\hline Educational technology obstacles & 0.789 \\
\hline Community service obstacles & 0.723 \\
\hline Obstacles to scientific research & 0.722 \\
\hline Organizational culture obstacles & 0.694 \\
\hline Educational curriculum obstacles & 0.766 \\
\hline obstacles of TQM implementation as all & $\mathbf{0 . 7 6 6}$ \\
\hline
\end{tabular}

Table (1) showed that the values of the internal consistency coefficient for the dimensions of obstacles of TQM implementation were accepted and ranged between (o.694-0.860). This indicates that Cronbach Alpha coefficient value for all dimensions of the instrument was higher than (o.6o), which means that the study instrument has internal consistency between items.

\subsection{Data Analysis}

In order to answer the questions of the study, the researcher used means, independent sample't' test and One Way ANOVA by SPSS software. The independent sample ' $t$ ' test is used when comparing two means with each other and preferred using Anova One Way when comparing three or more means (Cuevas, Febrero \& Fraiman, 2004). In order to interpret the results, means were adopted based on the Table mentioned below.

Table 2. Interpretation of means of Respondents' Answer for Each Item

\begin{tabular}{cc}
\hline Mean & Information \\
\hline $\mathbf{1 , 0 0 - 2 . 3 3}$ & Disagree (DA) \\
\hline $\mathbf{2 . 3 4 - 3 . 6 7}$ & Moderate Agree (MA) \\
\hline $3.68-5.00$ & Agree (A) \\
\hline
\end{tabular}

Source: (Bryman \& Bell, 2011)

\section{Findings and Discussion}

\subsection{Respondents Profile}

The descriptive analysis was used to describe the respondents' profile in terms of 'gender, academic ranking, and college'. The most of respondents were female representing $66.1 \%$, while $33.9 \%$ were male, respectively. With respect to the academic ranking of respondents, $76.9 \%$ of respondents were assistant professor ranking, while $13.0 \%$ of respondents were lecturers, followed by the respondents who ranking associate professor were represented $7.9 \%$, finally, the respondents who ranking professor were $2.2 \%$. With regard to the college, table 2 shows that the overwhelming mostly working in humanities colleges with a rate of $76.2 \%$, whiles those working in scientific colleges represented $23.8 \%$ from respondents. 
Table 3. The Respondent Profile ( $\mathrm{N}=277)$

\begin{tabular}{llcc}
\hline Variables & Category & $\mathbf{N}$ & $\mathbf{\%}$ \\
\hline \multirow{2}{*}{ Gender } & Male & 94 & 33.9 \\
& Female & 183 & 66.1 \\
\hline \multirow{3}{*}{ Academic ranking } & Lecturers & 36 & 13.0 \\
& Assistant professor & 213 & 76.9 \\
& Associate professor & 22 & 7.9 \\
& Professor & 3 & 2.2 \\
\hline \multirow{2}{*}{ College } & Humanities & 211 & 76.2 \\
& Scientific & 66 & 23.8 \\
\hline
\end{tabular}

\subsection{Research Question One}

In order to answer the first question of the study, the researcher used means and standard deviation for each item of measures obstacles to TQM implementation.

Table 4. Means and standard deviation for each item and for each dimension of obstacles to TQM implementation

\begin{tabular}{|c|c|c|c|c|}
\hline & Item & Mean & St.dev & Result \\
\hline & Top management obstacles & & & \\
\hline 1 & Weak human relations between top management and employees & 4.16 & 1.02 & A \\
\hline 2 & Top management is not satisfied with the application of total quality management & 4.12 & 1.06 & A \\
\hline 3 & Lack of understanding by top management of the needs of employees & 4.00 & 1.00 & A \\
\hline 4 & Top management neglects complaints and suggestions & 4.14 & 0.96 & A \\
\hline 5 & The administration is not interested in training staff to solve problems. & 3.64 & 1.24 & MA \\
\hline & Total & 4.01 & 0.73 & A \\
\hline & Students obstacles & & & \\
\hline 6 & The large number of students in the classroom. & 4.15 & 1.01 & A \\
\hline 7 & High repetition rates among students & 4.12 & 1.09 & A \\
\hline 8 & Poor student interaction within the classroom & 3.99 & 1.06 & A \\
\hline 9 & Reduced student motivation to learn & 3.97 & 1.07 & A \\
\hline 10 & Poor students' understanding of the concept of quality is the responsibility of all. & 3.72 & .99 & A \\
\hline & Total & 3.99 & 0.84 & A \\
\hline & Human resources obstacles & & & \\
\hline 11 & Imbalance between staff members and student numbers. & 3.46 & 0.96 & MA \\
\hline 12 & The use of traditional teaching methods by staff members & 3.49 & 0.95 & MA \\
\hline 13 & Lack of adequate knowledge of TQM by staff members. & 3.67 & 1.00 & MA \\
\hline 14 & Lack of trust and cooperation among staff members. & 3.57 & 1.06 & MA \\
\hline 15 & Scarcity of qualified staff members working faculty & 3.62 & 0.98 & MA \\
\hline & Total & 3.56 & 0.67 & MA \\
\hline & Financial resources obstacles & & & \\
\hline 16 & Lack of financial resources available to the faculty. & 3.80 & 1.07 & A \\
\hline 17 & The faculty does not rely on various sources of funding & 3.64 & 1.08 & MA \\
\hline 18 & Lack of participation of workers in funding the faculty & 3.29 & 0.98 & MA \\
\hline 19 & The lack of a specialized advisory office that supports the funding of the faculty & 3.48 & 1.03 & MA \\
\hline 20 & Lack of financial specialties to motivate employee. & 3.49 & 0.99 & MA \\
\hline & Total & 3.54 & 0.72 & MA \\
\hline & Educational technology obstacles & & & \\
\hline 21 & Failure to provide laboratories with sufficient tools to benefit academic programs & 4.10 & 1.00 & A \\
\hline 22 & Failure to provide classrooms to implement necessary academic programs & 4.00 & 1.02 & $\mathrm{~A}$ \\
\hline 23 & Weak educational materials needed for the academic programs offered & 4.04 & 1.02 & A \\
\hline 24 & Lack of electronic libraries and information search system & 3.93 & 1.10 & A \\
\hline & Dependence on traditional teaching methods and the lack of newer ones & 3.60 & 1.11 & MA \\
\hline & Total & 3.93 & 0.78 & $\mathbf{A}$ \\
\hline
\end{tabular}




\begin{tabular}{|c|c|c|c|}
\hline \multirow{2}{*}{$\begin{array}{l}\mathrm{N} \text { Item } \\
\text { Community service obstacles }\end{array}$} & \multicolumn{3}{|c|}{ Mean St.dev Result } \\
\hline & & & \\
\hline 26 Lack of joining faculty programs with development plans in the community & 3.69 & 1.17 & A \\
\hline 27 Lack of interest in the faculty to find jobs for its graduates & 3.63 & 1.13 & MA \\
\hline 28 Weak participation of the private sector in the faculty programs & 3.81 & 1.16 & $\mathrm{~A}$ \\
\hline 29 Lack of contribution of the faculty in solving realistic problems in society & 3.82 & 1.09 & A \\
\hline \multirow[t]{2}{*}{30 Lack of participation of faculty professors in seminars and conferences } & 3.55 & 0.98 & MA \\
\hline & 3.70 & 0.76 & $\mathbf{A}$ \\
\hline \multicolumn{4}{|l|}{ Obstacles to scientific research } \\
\hline 31 Scientific research does not emphasis on contemporary topics & 3.82 & 1.06 & A \\
\hline 32 Lack of moral incentives provided to enrich scientific research & 3.64 & 1.07 & MA \\
\hline 33 Lack of financial budget allocated for scientific research within the budget of the faculty & 3.74 & 1.09 & A \\
\hline 34 Lack of publications of refereed scientific journals & 3.76 & 1.04 & A \\
\hline 35 Weak cooperation between faculty and government institutions & 3.64 & 0.92 & MA \\
\hline Total & $3 \cdot 72$ & 0.71 & $\mathbf{A}$ \\
\hline \multicolumn{4}{|l|}{ Organizational culture obstacles } \\
\hline 36 Negative organizational climate for the culture of TQM & 3.77 & 1.01 & A \\
\hline 37 Misunderstanding of the human aspects of the employee & 3.83 & 1.08 & A \\
\hline 38 Weakness of the university's readiness to change its culture to suit the requirements of TQM & 3.88 & 1.06 & A \\
\hline 39 Low constructive dialogue with staff to educate them on TQM principles & 3.70 & 1.05 & A \\
\hline 40 Lack of clarification of quality culture among employee & 3.66 & 0.97 & MA \\
\hline Total & 3.77 & 0.69 & $\mathbf{A}$ \\
\hline \multicolumn{4}{|l|}{ Educational curriculum obstacles } \\
\hline 41 Low capacity of educational curricula to accommodate the variables of the age & 3.84 & 1.18 & A \\
\hline 42 Inadequate educational curricula for the labor market & 3.49 & 1.10 & MA \\
\hline 43 The inability of the educational curricula to equip the student with problem solving skills & 3.67 & 1.05 & MA \\
\hline 44 Weak educational curricula 'ability to establish high values & 3.59 & 1.03 & MA \\
\hline 45 The curriculum does not fulfill the student's wishes and tendencies & 3.42 & 1.03 & MA \\
\hline Total & 3.60 & 0.77 & MA \\
\hline Over all & 3.76 & 0.31 & $\mathbf{A}$ \\
\hline
\end{tabular}

Table 4 showed that the mean value of top management obstacles was (4.01) with a standard deviation of (o.73). This means that the TQM from the point of view of faculty members at Imam Abdulrahman bin Faisal University is not supported by top management. Item 1, which states, "Weak human relations between top management and employees" has the highest means value among the items of the top management obstacles with (4.16). While item 5, which states, "The administration is not interested in training staff to solve problems" has the lowest value of the means among the items with (3.64). Also, Table 4 showed that the mean value of students' obstacles was (3.99) with a standard deviation of (o.84). This means that the obstacles related to students from the point of view of faculty members at Imam Abdulrahman bin Faisal University are hinder TQM implementation. Item 6, which states, "The large number of students in the classroom" has the highest means value among the items of students' obstacles with (4.15). While item 10, which states, "Poor students' understanding of the concept of quality is the responsibility of all" has lowest value of the means among the items with (3.72). In addition, Table 4 shows that the mean value of the human resources obstacles was (3.56) with a standard deviation of (o.67). This means that the human resources obstacles from the point of view of faculty members at Imam Abdulrahman bin Faisal University are moderately significant. Item 13, which states, "Lack of adequate knowledge of TQM by staff members" has the highest means value among the items of the human resources obstacles with (3.67). While item 11, which states, "Imbalance between staff members and student numbers" has the lowest value of the means among the items with (3.46).

As regards financial resources obstacles, the results showed that the mean value of it was (3.54) with a standard deviation of (o.72). This means that the financial resources obstacles from the point of view of faculty members at Imam Abdulrahman bin Faisal University are moderately significant. Item 16, which state, "Lack of financial resources available to the faculty" has the highest means value 
among the items of the financial resources obstacles with (3.80). While item 18, which states, "Lack of participation of workers in funding the faculty" has the lowest value of the means among the items with (3.29). In relation to educational technology obstacles, the results showed that the mean value of it was (3.93) with a standard deviation of (0.78). This means that the educational technology obstacles from the point of view of faculty members at Imam Abdulrahman bin Faisal University are highly significant. Item 21, which state, "Failure to provide laboratories with sufficient tools to benefit academic programs" has the highest means value among the items of the educational technology obstacles with (4.10). While item 25, which states, "Dependence on traditional teaching methods and the lack of newer ones" has the lowest value of the means among the items with (3.60). As regard to community service obstacles, the results showed that the mean value of it was $(3.70)$ with a standard deviation of (o.76). This means that the community service obstacles from the point of view of faculty members at Imam Abdulrahman bin Faisal University are highly significant. Item 29, which state, "Lack of contribution of the faculty in solving real problems in society" has the highest means value among the items of the community service obstacles with (3.82). While item 30, which states, "Lack of participation of faculty professors in seminars and conferences" has the lowest value of the means among the items with (3.55).

The results in the above table also showed that the mean value of obstacles to scientific research was (3.72) with a standard deviation of (o.71). This means that the obstacles to scientific research from the point of view of faculty members at Imam Abdulrahman bin Faisal University are highly significant. Item 31, which state, "Scientific research does not emphasis on contemporary topics" has the highest means value among the items of the obstacles to scientific research with (3.82). While item 32 and 35, which states, "Lack of moral incentives provided to enrich scientific research"; "Weak cooperation between faculty and government institutions", respectively have the lowest value of the means among the items with (3.64). In relation to organizational culture obstacles, the results showed that the mean value of it was (3.77) with a standard deviation of (0.78). This means that the organizational culture obstacles from the point of view of faculty members at Imam Abdulrahman bin Faisal University are highly significant. Item 38, which state, "Weakness of the university's readiness to change its culture to suit the requirements of TQM" has the highest means value among the items of the organizational culture obstacles with (4.88). While item 40, which states, "Lack of clarification of quality culture among employee" has the lowest value of the means among the items with (3.66). As regards to educational curriculum obstacles, the results showed that the mean value of it was (3.60) with a standard deviation of (0.77). This means that the educational curriculum obstacles from the point of view of faculty members at Imam Abdulrahman bin Faisal University are moderately significant. Item 41 , which state, "Low capacity of educational curricula to accommodate the variables of the age" has the highest means value among the items of the educational curriculum obstacles with (3.84). While item 45, which state, “The curriculum does not fulfill the student's wishes and tendencies" has the lowest value of the means among the items with (3.42).

This can refer to that faculty members have different views related to quality and the lack of managers knowledge about the TQM significance, the diffusion of authoritarian administration approaches, and conventional management styles at Imam Abdulrahman bin Faisal University, this result agrees with studies of Alnajjar and Jawad (2019); Hassan (2016) and Kigozi (2019), but it differs with the study of Sabra et al. (2020). Also, this study showed that faculty members agreed that obstacles related to students and the students do not awareness the quality concept, this back to lack of circumstances that enhance the culture of quality of students due to the growth of students' numbers with the shortage in equipment and building in universities. This result agrees with the study of Sabra et al. (2020). Regarding human resources obstacles, the results demonstrated that the faculty members moderately agreed that the obstacles were a lack of sufficient TQM awareness by faculty members and a lack of faculty members qualified in colleges, this result consistent with AlKigozi (2019) who indicated that the main barriers to apply TQM back to the shortage of awareness mechanisms for self-assessment, lack arrangement between departments and staff and Inadequate attention in training. 
With respect to barriers of financial resources, the result of this study pointed that the majority of respondents moderately agreed that most barriers were the shortage of financial support for the faculty members and the college does not depend on diverse funding sources. This result may since Imam Abdulrahman bin Faisal University does not create an annual financial plan based on the needs of the faculty, and agrees with the result of the study Al-Daibat and Al-Daibat (2016) revealed that resources of financial are very helpful in the TQM applying procedures. In addition, Kigozi (2019) emphasized that inadequate resources and funding were key obstacles to the applying of TQM successfully. In relation to educational technology obstacles. The findings of this study showed that laboratories were not able to provide adequate resources to support academic programs and to provide classrooms with the requisite academic programs and reliance on conventional teaching methods, and agrees with the result of the study Al-Daibat and Al-Daibat (2016) who revealed that the main difficulties in the application of TQM are the shortage of infrastructural facilities. In relation to barriers to community service, the findings revealed that academic staff believed that the faculty's lack of contribution to addressing real problems in society and the private sector's poor involvement in faculty programs were the key obstacles. This finding is congruence with Al-Daibat and Al-Daibat (2016) and Sabra et al. (2020) which stated that the community plays a remarkable role in uplifting and enriching institutional progress and is therefore considered to be an influential and contributory factor in achieving predetermined educational goals; the role of the community in the implementation of TQM can not be ignored.

Concerning obstacles to scientific research, the results showed that major of the faculty members agreed that most obstacles were scientific research does not emphasize contemporary topics and lack of publications of refereed scientific journals. This may be because of the fact that universities face major financial resource challenges, the lack of external circumstances changes impacting financial resources, such as growing students numbers, In the same context Sabra et al. (2020) concluded that preparation, techniques, and tools that facilitate the identification and reward of desired behaviors and practices are important to encourage readiness for changes and develop the preparation level for the implementation of TQM. As regard organizational culture obstacles, the results showed that the majority of faculty members agreed that obstacles were the weakness of the readiness of the university to change its culture to suit TQM requirements and misunderstanding of the employee's human aspects, this result agrees with Al-Daibat and Al-Daibat (2016) and Sabra et al. (2020) stressed that influential TQM implementation requires influential organizational environment reforms and ensures a suitable and an organizational culture that is supportive and an appropriate quality culture climate. With regard to obstacles of educational curriculum, the result showed that most of the faculty members moderately agreed that obstacles were low educational curriculum capacity to accommodate age variables and the inability of the curriculum to equip the student with problem-solving abilities. In the same respect, Sabra et al. (2020) explored that the curriculum was an obstacle to the application of TQM.

\subsection{Research Question Two}

In order to answer the second question of the study, The independent sample ' $t$ ' test and Anova One Way was used to identify the significance of statistical differences in the obstacles to the application of total quality management in Saudi universities from the viewpoint of faculty members according to the variables of gender, academic rank, and college.

Table 5. Independent Samples T- test of gender and college

\begin{tabular}{lcccccc}
\hline Variables & N & Mean & St.dev & df & t & Sig \\
\hline Male & 94 & 3.71 & 0.34 & 275 & 1.73 & 0.085 \\
Female & 183 & 3.78 & 0.30 & & & \\
\hline Humanities & 211 & 3.77 & 0.30 & 275 & 1.40 & 0.163 \\
Scientific & 66 & 3.71 & 0.34 & & & \\
\hline \multicolumn{7}{c}{\begin{tabular}{c}
0 \\
\multicolumn{2}{c}{198}
\end{tabular}}
\end{tabular}


Table (5) showed that the mean of responses male for TQM was (3.71) and the mean of responses female was (3.78). Also, the table showed that the mean of responses humanities colleges for TQM was (3.71) and the mean of responses scientific colleges was (3.78). In addition, the Sig of two groups of gender is (0.085) and Sig of two groups of colleges is (0.163), which means that there are no significant impact of gender and colleges according to the point of view of faculty members about obstacles of TQM implementation. These results converge with the results of Al-Daibat and AlDaibat (2016) and Sabra et al. (2020).

Table 6. ANOVA test of Academic Ranking

\begin{tabular}{|l|l|c|c|c|c|c|}
\hline Variable & Gropus & Sum of Squares & df & Mean Square & F & Sig \\
\hline \multirow{4}{*}{ Academic Ranking } & Between groups & 0.178 & 3 & 0.059 & 0.604 & 0.613 \\
\cline { 2 - 7 } & Within groups & 26.78 & 273 & 0.098 & & \\
\cline { 2 - 7 } & Total & 26.95 & 276 & & & \\
\hline
\end{tabular}

Table (6) showed that there are no differences among groups according to academic ranking. Where, the Sig is (o.613), which indicates no statistically significant effect $(\alpha \leq 0.05)$ of academic ranking based on faculty members' point view about obstacles of TQM. This result consistent with studies of AlDaibat and Al-Daibat (2016) and Sabra et al. (2020).

\section{Conclusions}

This study aimed to introduce the concept of TQM and determine the obstacles of TQM implementation at Imam Abdulrahman bin Faisal University. The result showed that top management obstacles, human resources obstacles, student's obstacles, financial resources, educational technology obstacles, community service obstacles, obstacles to scientific research, organizational culture obstacles, and educational curriculum obstacles are affecting on implementation of TQM at Imam Abdulrahman bin Faisal University from point of view faculty members. The results showed the top management obstacles came in the first rank among the obstacles that affect TQM implementation, followed by student's obstacles, while financial resources obstacles and human resources obstacles come in the last obstacles affect TQM implementation at Imam Abdulrahman bin Faisal University from point of view faculty members.

Based on the above turns out that universities follow central planning, there is a lack of communication with the Saudi community to participate in development plans through continuous education programs provided to community members; the student is not the focus of the strategic planning process, and the lack of infrastructure that is used to implement TQM.

\section{References}

Abd-Elwahed, M. S., \& El-Baz, M. A. (2018). Impact of implementation of total quality management: An assessment of the Saudi industry. South African Journal of Industrial Engineering, 29(1), 97-107.

Abu Saa, J., Wahbi, D., \& Kloob, M. (2019). Obstacles of the Application of Total Quality Management at Palestine Technical University - Khadoorie from the Point of View of Faculty Members. International Journal for Quality Assurance, 2(1), 81-90.

Al-Daibat, B., \& Al-Daibat, M. (2017). Impediments of Total Quality Management Application at Higher Education Institutions. European Journal of Business and Management, 8(36), 44-55.

Al-Kayed, R. I., \& Al-Tahrawi, M. H. (2020). Barriers Facing Total Quality Management Principles Implementation at Princess Alia University College/Al-Balqa Applied University from Teaching Staff Perspective. Multicultural Education, 6(4).

Alkhatib A., \&Alkhatib R., (2016): TQM Educational Applications, the 8th ed., Irbid, Jordan: the Modern Book World for Publication and Distribution. 
Almurshidee, K. A. (2017). The implementation of TQM in higher education institutions in Saudi Arabia: Marketing prospective. Global Journal of Management and Business Research.

Al-Najjar, S. M., \& Jawad, M. K. (2019). Total Quality Management Practices and Impediments in the Arab Countries with Special Reference to Iraq. Journal of Law and Society, 6(1), 86-96.

Armor, T. B., Jnidi, A. F., \& Alaqramaiti, A. F. M. (2019). Obstacles to the application of total quality management at the University of Prince Sattam bin Abdul Aziz in the light of some variables. Basic Education College Magazine For Educational and Humanities Sciences, (43).

Bruçaj, S. (2019). Quality Management in Higher Education; Challenges of Private Universities in Albania. European Journal of Education, 1(3), 194-202.

Bryman, A., and Bell, E. (2011) Business Research Methods, 3rd Ed. Oxford University Press. Oxford.

Cuevas, A., Febrero, M., \& Fraiman, R. (2004). An anova test for functional data. Computational statistics $\mathcal{E}$ data analysis, 47(1), 111-122.

Ezeani, N. S., \&. Ibijola, E. Y. (2017). The conversion process in the university system: Nigerian university students' assessment. Journal of Educational Research and Reviews, 5(2), 14-20.

Hasan, K., Islam, M. S., Shams, A. T., \& Gupta, H. (2018). Total quality management (TQM): Implementation in primary education system of Bangladesh. International Journal of Research in Industrial Engineering, 7(3), $370-380$.

Hassan, H. (2014). Obstacles to the application of total quality management at parallel master's program in the Faculty of Social Sciences in Imam Muhammad bin Saud Islamic University in Riyadh. Journal of Arabic Studies in Education and Psychology, 47 (3), 105- 144, Arab educators Association, Riyadh, Saudi Arabia.

Hossin, MMI., Islam, MA., \& Uddin, M. (2020). Implementation of TQM in Public Universities of Bangladesh: Challenges and Resolutions: A Review. Saudi Journal of Business and Management Studies, 3(12), $1338-1347$.

Kigozi, E., \& On, J. K. Y. (2019). Total Quality Management (TQM) Practices Applied in Education Institutions: A Systematic Review of Literature. International Journal of Innovative Business Strategies, 5(2), 341-352.

Kistiani, D. P., \& Permana, J. (2020). The Importance of Application Total Quality Management at Higher Education. In 3 rd International Conference on Research of Educational Administration and Management (ICREAM 2019) (pp. 177-180). Atlantis Press.

Pushpa, L. (2016). Implementation of total quality management in higher education institutions. International Journal of Scientific Engineering and Research (IJSER), 1(5).

Ravindran, N., \& Kamaravel, R. K. (2016). Total quality management in education: Prospects, issues and challenges. Shanlax Int. J. Educ, 4(2), 58-65.

Sabra, H. I., Abd El Zaher, O. M., \& Mohamed, S. S. (2020). Obstacles of Implementing Total Quality Management in Higher Education Institutions: Academic Staff perspective. Assiut Scientific Nursing Journal, 8(23), 49-61.

Sajjad, Z., \& Syed, T. H. (2017). Analysis of Challenges to Total Quality Management Implementation in FGEIs $(\mathrm{C} / \mathrm{G})$ in Pakistan. European Journal of Business and Management, 9(13).

Saunders, M., Lewis, P., \& Thornhill, A. (2016). Research methods for business students (Seventh). Nueva York: Pearson Education.

Setiawan, A. (2019). Implementation of Total Quality Management (TQM) in Raising the Quality of Education in Private Madrasah Tsanawiyah. JKP $\mid$ Jurnal Kepemimpinan Pendidikan, 2(2), 269-284.

Surendran, S. (2018). Application of Total Quality Management in Education-An Analysis. International Journal of Management and Humanities (IJMH), 3(5), 1-5.

Talapatra, S., \& Uddin, M. K. (2018, March). Some obstacles that affect the TQM implementation in Bangladeshi RMG Sector: An empirical study. In Proceedings of the 8th International Conference on Industrial Engineering and Operations Management, Bandung (pp. 6-8).

Wani, I. A., \& Mehraj, H. K. (2014). Total quality management in education: An analysis. International Journal of Humanities and Social Science Invention, 3(6), 71-78.

Zanqar, F. S. M., Khatibi, A., Azam, S. F., \& Tham, J. (2019). The Relationship between Total Quality Management and Service Quality in Higher Education of UAE. European Journal of Human Resource Management Studies. 